\title{
Investigation of 1,1-didecyl-4,4-bipyridine and 1,1-didecyl-2,2- bipyridine as Corrosion Inhibitors for Carbon Steel in Hydrochloride Acid Solution
}

\author{
Xian He ${ }^{1}$, Lu Chen ${ }^{1}$, Yang Tian ${ }^{1}$, Fubin Ma ${ }^{2}$, Xi Huang ${ }^{1,3}$, Kun Cao ${ }^{1, *}$ \\ ${ }^{1}$ Department of Chemistry \& Chemical Engineering, Neijiang Normal University, Neijiang, Sichuan, \\ 641112, PR China \\ ${ }^{2}$ Institute of Oceanology, Chinese Academy of Sciences, Qingdao, 266000, China \\ ${ }^{3}$ Material Corrosion and Protection Key Laboratory of Sichuan province, Sichuan University of Science \\ and Engineering, Zigong, Sichuan, 643000, PR China \\ *E-mail: kevincao0811@,126.com
}

doi: $10.20964 / 2020.12 .36$

Received: 19 July 2020 / Accepted: 22 September 2020 / Published: 31 October 2020

Bipyridine surfactants (BPSs) were analyzed as corrosion inhibitors for mild steel in $1 \mathrm{~mol} \cdot \mathrm{L}^{-1} \mathrm{HCl}$. The corrosion behavior was evaluated using weight loss method, potentiodynamic polarization, and electrochemical impedance spectroscopy. The results show that the anticorrosive efficiency increased with increasing concentration of BPSs. In addition, BPSs behaved as a mixed-type inhibitor based on the anode. The surface of steel was examined by scanning electron microscopy, atomic force microscopy, and X-ray phosphorescence spectroscopy. The elemental analysis of the chemical states on the surface indicated that BPSs adsorbed on mild steel surface to prevent corrosion.

Keywords: mild steel; corrosion inhibitor; bipyridine; electrochemical

\section{FULL TEXT}

(C) 2020 The Authors. Published by ESG (www.electrochemsci.org). This article is an open access article distributed under the terms and conditions of the Creative Commons Attribution license (http://creativecommons.org/licenses/by/4.0/). 